\title{
RECONSTRUCTION OF THE PALEOTEMPERATURE IN THE SOUTHERN MARGIN OF THE TAKLIMAKAN DESERT BASED ON CARBON ISOTOPE DISCRIMINATION OF TAMARIX LEAVES
}

\author{
ZHANG, Z. G. ${ }^{1 *}-$ FANG, Y. ${ }^{1}-$ LI, L. ${ }^{1}-$ SUN, Z. Y. ${ }^{1}-$ ZHAO, Y. J. ${ }^{1}-$ XIA, X. C. ${ }^{2}-$ ASHRAF, M. A. ${ }^{3}$ \\ ${ }^{1}$ College of Resources and Environmental Sciences, Hebei Normal University, Hebei Key \\ Laboratory of Environmental Change and Ecological Construction \\ Shijiazhuang 050024, China \\ ${ }^{2}$ Xinjiang Institute of Ecology and Geography, Chinese Academy of Sciences \\ Urumqi 830011, China \\ ${ }^{3}$ International Water, Air \& Soil Conservation Society, 59200 Kuala Lumpur, Malaysia \\ (phone/fax: +86-311-80789804) \\ *Corresponding author \\ e-mail:43281358@qq.com \\ (Received $8^{\text {th }}$ Mar 2017; accepted $7^{\text {th }}$ Jun 2017)
}

\begin{abstract}
Environmental factors affect carbon isotope discrimination in plants. Therefore, carbon isotope discrimination records a wealth of environmental information, such as temperature, precipitation etc., and the predominant factor's influence is significant. Based on this hypothesis, we determined the carbon isotope composition of Tamarix growing in the southern margin of the Taklimakan Desert where temperature and water are key growth-limiting factors. Mean annual temperature (MAT) showed a significant impact on variation in carbon isotope discrimination value (DS), but precipitation not. In multiple stepwise regression analysis, MAT was the first and the only variable selected into the prediction model of DS against MAT and precipitation, indicating that the effect of temperature on carbon isotope discrimination was predominant. The correlation between DS and the variation rate of precipitation in previous year shows that precipitation, as a major factor in arid regions, exerts a certain "lag effect" on the growth of Tamarix. The reconstructed MAT regression model was established according to the DS with the least squares method, the result bolster the argument that the planet's temperatures have shifted significantly in the last half-century.
\end{abstract}

Keywords: Tamarix cone sediment laminae; temperature; precipitation; climatic factor; regression model

\section{Introduction}

Plant carbon isotope discrimination in photosynthesis is closely associated with physiological responses including stomata conductance, assimilation rate, altered C:N allocation to carboxylation, and leaf structure (Seibt et al., 2008; Liu et al., 2014). It may be affected by many environmental factors such as temperature, moisture, altitude, latitude, longitude, solar radiation, air pressure, and atmospheric $\mathrm{CO}_{2}$ concentration (Wang et al., 2003; Treydte et al., 2007). Based on Farquhar's research (1982), the fundamental mechanism is that these factors can control directly or indirectly the ratio of the intercellular $\mathrm{CO}_{2}$ concentration (ci) to the ambientCO $\mathrm{O}_{2}$ concentration (ca) to affect plant carbon isotope discrimination.

Some studies have reported that precipitation has a positive influence on plant carbon isotope discrimination and altitude a negative, but that of the temperature is varied (e.g., 
Körner et al., 1988, 1991; Morecroft and Woodward, 1996; Wang et al., 2008, 2013; Diefendorf et al., 2010; Kohn, 2010; Xu et al., 2015) inferred that the effect of altitude, longitude and latitude on plant carbon isotope discrimination could be expressed mainly in the effects of temperature and precipitation. Some researchers believed that the effects of solar radiation and air pressure are rather small compared to temperature and/or precipitation (Körner et al., 1988, 1991; Sparks and Ehleringer, 1997; Wang et al., 2008). Temperature and precipitation are considered as two fundamental influential factors.

Since plant carbon isotope discrimination is closely related to its performance, in which the key growth-limiting factors play a significant role. It has been suggested that the key growth-limiting factor is also the predominant factor affecting plant carbon isotope discrimination (Winter et al., 1982; McCarroll and Loader, 2004). Thus carbon isotope discrimination records the information of the environment when and where the plant grows, is a good carrier which can be used to reconstruct the factors of climate and the environment in history (Wei et al., 2005).

In this study, Tamarix leaf carbon isotope composition $(\delta 13 \mathrm{C})$ were investigated in the southern margin of the Taklimakan Desert (TDSM), the data of temperature and precipitation of 1960-2011 was obtained from the Cele Meteorological Station, which is closest to and the same altitude with the sampling site (Figure 1), the correlations was analyzed between the plant carbon isotope discrimination (DS) and temperature and precipitation. The objective was to assess whether or not temperature and precipitation can exert a dominant impact on the growth of Tamarix and reconstruct them.

\section{Material and method}

\section{Study area}

The area being studied is located in Cele Oasis, which belongs to Hotian Prefecture of Xinjiang Uygur Autonomous Region, China, in TDSM. The Cele Oasis is one of hundreds of oases, large or small, such as Hotian Oasis, Yutian Oasis and Minfeng Oasis. It lies on the transition zone between the Taklimakan Desert and Kunlun Mountains, the upstream area of Celeriver's alluvial fan, and belongs to continental arid desert climate, with an annual average temperature of $12.13{ }^{\circ} \mathrm{C}$ and frequent wind sandy activities. According to the data gathered from Cele Meteorological Station, the annual precipitation is only $38.4 \mathrm{~mm}, 50 \%$ to $70 \%$ of which concentrates in the period from June to September; but the annual average evaporation can reach to $2500 \sim 3400 \mathrm{~mm}$. The zonal vegetation is mainly made up of the xerophilous, super-xerophytic shrubs and semi-shrubs, as well as some alkali-saline-tolerant perennial herbs.

On both sides of riverbanks, delta areas, ancient riverbanks and local lowlands of the rivers, there are scattered Tamarixes, taking carbon from the air and oxygen and hydrogen from deep soil, standing fixed in the desert area often for centuries. Their unique physical characteristics enable them to survive in the arid, high salt desert regions. The longtime collaboration between wind sandy and Tamarix has formed Tamarix cones, a unique bio-geographical type, composed of alternate layers of sand and Tamarix twigs and leaves (Xia et al., 2004). 


\section{Sample collection}

From June $18^{\text {th }}$ to $20^{\text {th }}$ in 2011 , in Damagou of Cele County (Fig. 1), a typical Tamarix cone was chosen. From top to bottom, the samples were collected layer by layer. If the sedimentary vein was not clear, they were collected accorded to the average thickness. The sample site is located at $37.09^{\circ} \mathrm{N}, 81.08^{\circ} \mathrm{E}, 1318 \mathrm{~m}$ above sea level; 151 samples of sedimentary veins of Tamarix cones were collected. The depth of the profile is about $4.5 \mathrm{~m}$.

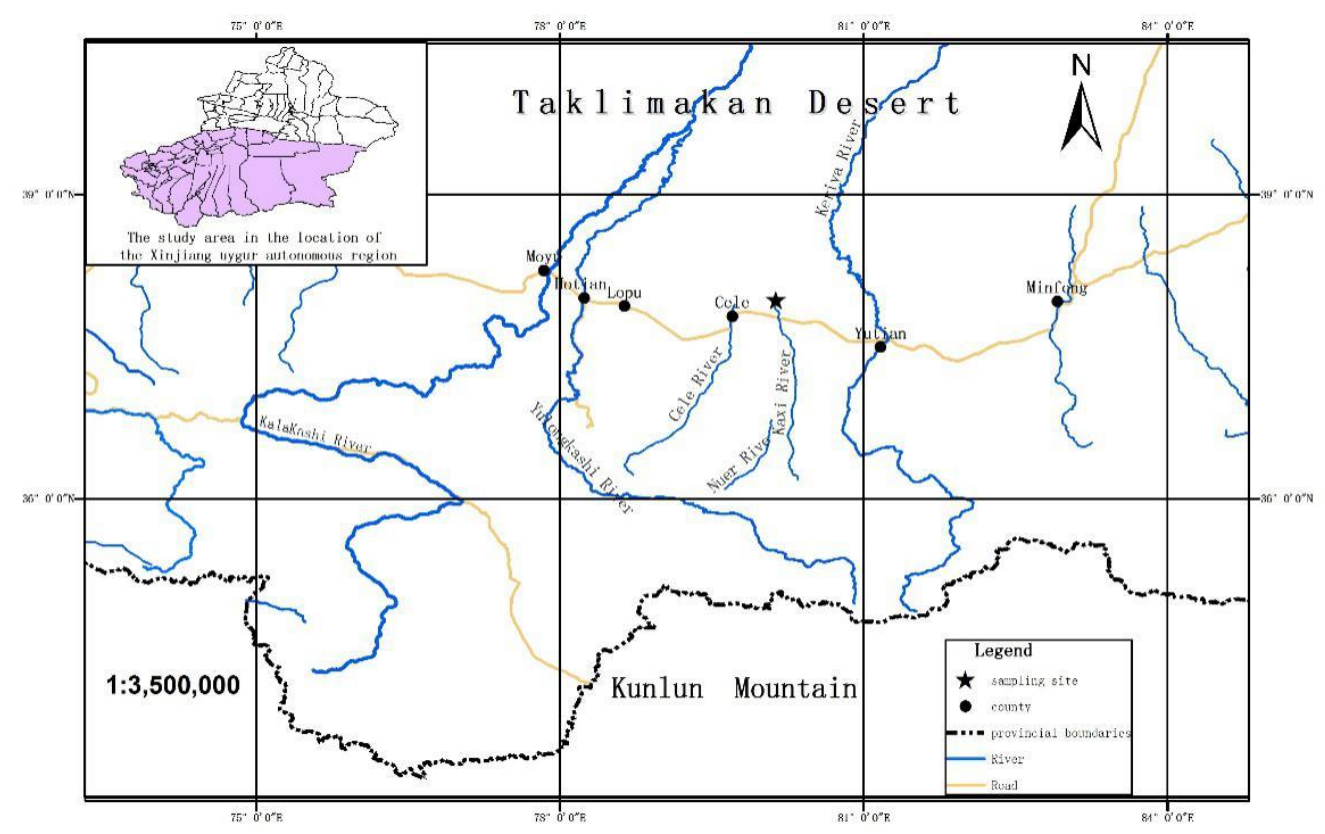

Figure 1. Location map of sampling site in Damagou of Cele County

\section{Data measurement}

The age sequence of $\delta 13 \mathrm{C}$ values was identified according to overall consideration of the age data derived from $210 \mathrm{~Pb}, 137 \mathrm{Cs}$ dating methods, which were done in Nanjing Institute of Geography and Limnology, Chinese Academy of Sciences (CAS), combined with the calculation of 14C dating, which was done by the Accelerator Mass Spectrometry Laboratory in Beijing University, the rate of Tamarix cone sedimentation and the thickness of the each sedimentary layer (Zhao et al., 2015).

The $\delta 13 \mathrm{C}$ values of all samples were measured in Nanjing Institute of Geography and Limnology CAS, on the base of VPDB (the standard error of $0.1 \%$ ). The test steps are as follow: after the collected leaves were well pretreated, the obtained alpha cellulose was burned by Flash EA1112 Eelemental Analyzer; the combusted gas was sent into Delta Plus Advantage Isotope Mass Spectrometer to measure organic carbon isotope ratio of the sample $(13 \mathrm{C} / 12 \mathrm{C})$.

The carbon isotope discrimination (DS) of Tamarix leaves is obtained by following formula based on Farquhar et al. (1989):

$$
D S=\frac{\left(\delta^{13} C_{a t e}-\delta^{13} C_{t}\right)}{\left(1+\delta^{13} C_{t} / 1000\right)} \approx \delta^{13} C_{a t e}-\delta^{13} C_{t}
$$


In Eq. 1, the carbon isotope ratio of atmospheric $\mathrm{CO}_{2}$, which were measured from ice core bubbles or plant $\delta 13 \mathrm{C}$ value (Friedli et al., 1986; Leavitt and Long, 1989; McCarroll and Loader, 2004), $\delta^{13} C_{t}$ is the carbon isotope ratio of Tamarix leaves.

\section{Statistical analysis}

Descriptive statistical analysis was carried out on $\delta 13 \mathrm{C}$ and DS, then a bivariate correlation analysis was performed to examine the links between plant DS and temperature and precipitation. Considering the existence of potential interactions between temperature and precipitation, partial correlation analysis, in which temperature and precipitation were separately controlled, was applied to describe the actual links between Tamarix leaf DS and temperature and precipitation. Regression analysis was used to constrain the influences of temperature and precipitation on Tamarix leaf DS. The regression models were established according to the Tamarix leaf DS with least square fitting method to reconstruct the history climate information. All statistical analysis was performed using IBM SPSS Statistics 19.0 (IBM Corporation, New York, NY, USA).

\section{Results}

\section{The $\delta^{13} C$ and $D S$}

The $\delta^{13} \mathrm{C}$ values of the sample site were established in the period from 1590 to 2010 (Figure $2 a$ ). The time span of this sampling sequence is 420 years. The $\delta^{13} \mathrm{C}$ values are within the range from $-25.008 \%$ to $-23.138 \%$, the average $\delta^{13} \mathrm{C}$ value is $-24.137 \%$. In the period from 1790 to 1937 , the $\delta 13 \mathrm{C}$ value is lower and fluctuates frequently. In $1790,1832,1881$ and 1933, the relatively low values appear, which are $-24.625 \%$, $24.824 \%$, $-25.008 \%$ and $-24.938 \%$ respectively, and in 1881 the minimum value of the data series appears. There is a leap in 1939, 3.6\% higher than that in 1937, and the $\delta^{13} \mathrm{C}$ value is greater and more dynamic till 2010, with the emergence of a maximum value of $-23.138 \%$ in 1997. In 1982, 1957 and 1954, the $\delta 13 \mathrm{C}$ value is higher, but in 1974 it appears as a relatively lower value for this period.

The carbon isotope discrimination values (DS) were obtained by formula (1) (Figure $2 b$ ). The values are within the range from $15.228 \%$ o to $18.458 \%$, the average DS value is 17.372 , and show a downward trend.

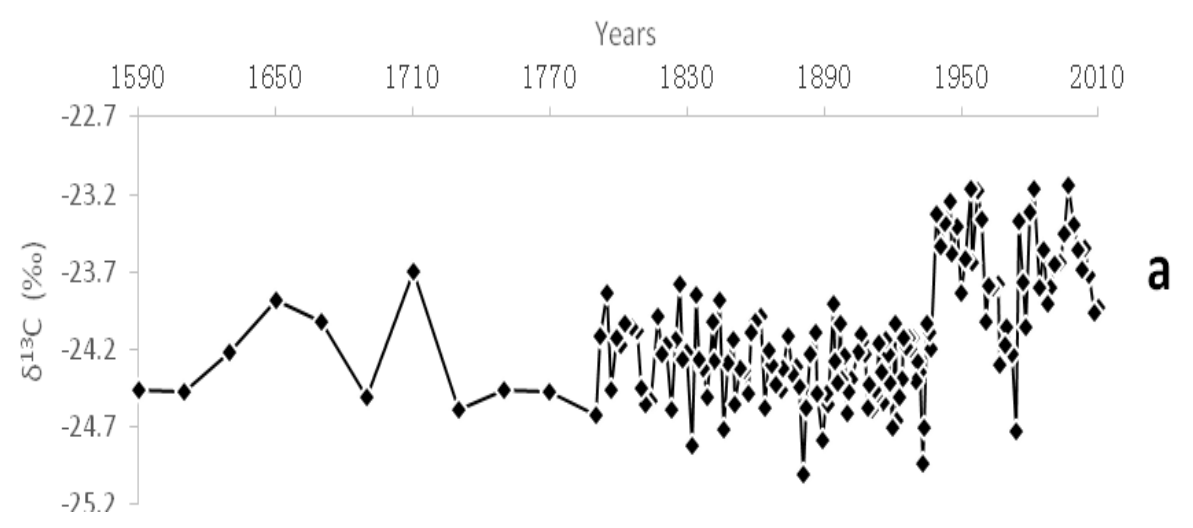




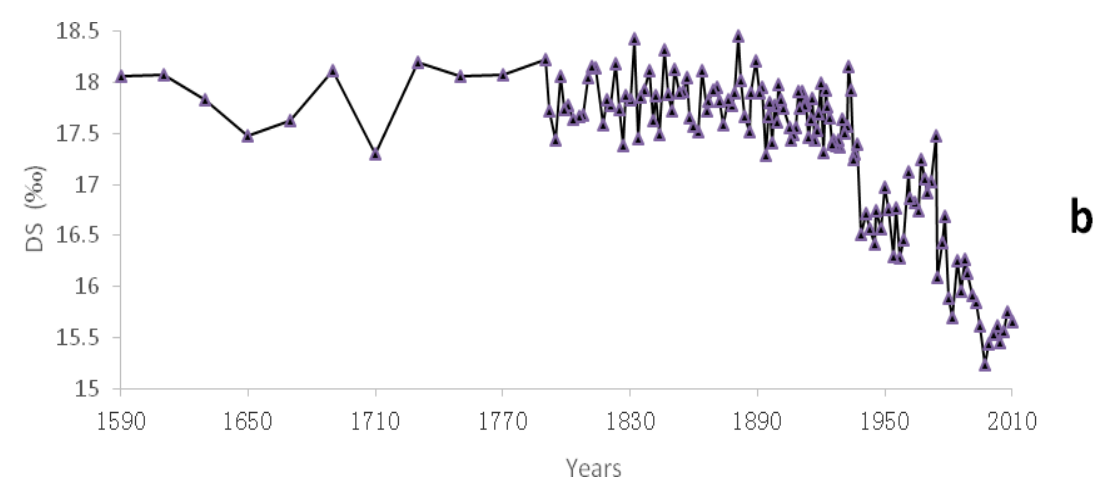

Figure 1. The observed sequences of the $\delta 13 C$ values (a) and the carbon isotope discrimination values $(b)$

\section{Correlations analysis}

The correlation between the $\delta^{13} \mathrm{C}$ values and temperature and precipitation and that between DS and temperature and precipitation are showed in Table 1. Considering that the response of carbon isotope and carbon isotope discrimination to environmental factors may be dependent on Tamarix functional type, the influence of temperature and precipitation on $\delta 13 \mathrm{C}$ and DS were analyzed separately.

There was a positive correlation between temperature and $\delta 13 \mathrm{C}$ only in February $(\mathrm{r}=0.510, \mathrm{p}=0.005)$. The DS values were correlated with the temperature in February and growing season, and significantly with mean annual temperature (MAT) ( $\mathrm{r}=-0.761$, $\mathrm{p}=0.000$ ).

The $\delta^{13} \mathrm{C}$ values were correlated with precipitation only in February $(\mathrm{r}=0.488$, $\mathrm{p}=0.007$ ) of that year, and the DS values were not associated with precipitation either in that year or previous year. But the precipitation changes rate of previous year (PCR) (i.e., the natural logarithm of the precipitation in the previous year) were correlated with DS $(\mathrm{r}=-0.376, \mathrm{p}=0.044)$ (shown as Table 2).

Table 1. The correlation between the $\delta 13 C, D S$ values and temperature and precipitation $(N=29)$

\begin{tabular}{|c|c|c|c|c|c|c|c|c|}
\hline & \multicolumn{2}{|c|}{$\begin{array}{c}\text { Between } \delta^{13} \mathrm{C} \text { and } \\
\text { Temperature }\end{array}$} & \multicolumn{2}{c|}{$\begin{array}{c}\text { Between DS and } \\
\text { Temperature }\end{array}$} & \multicolumn{2}{c|}{$\begin{array}{c}\text { Between } \delta^{13} \mathrm{C} \text { and } \\
\text { Precipitation }\end{array}$} & \multicolumn{2}{c|}{$\begin{array}{c}\text { Between DS and } \\
\text { Precipitation }\end{array}$} \\
\cline { 2 - 8 } & Correlation & Sig. & Correlation & Sig. & Correlation & Sig. & Correlation & Sig. \\
\hline Jan & 0.312 & 0.1 & -0.311 & 0.101 & -0.362 & 0.053 & 0.117 & 0.545 \\
Feb & $\mathbf{0 . 5 1 0}$ & $\mathbf{0 . 0 0 5}$ & $\mathbf{- 0 . 4 4 5 *}$ & $\mathbf{0 . 0 1 5}$ & $\mathbf{- 0 . 4 8 8 * *}$ & $\mathbf{0 . 0 0 7}$ & 0.2 & 0.297 \\
Mar & 0.109 & 0.575 & -0.305 & 0.108 & -0.026 & 0.894 & -0.224 & 0.243 \\
Apr & -0.143 & 0.46 & -0.016 & 0.934 & -0.07 & 0.718 & 0.142 & 0.462 \\
May & -0.052 & 0.788 & -0.181 & 0.346 & -0.209 & 0.276 & 0.13 & 0.500 \\
Jun & 0.149 & 0.442 & -0.229 & 0.232 & -0.074 & 0.703 & -0.114 & 0.556 \\
Jul & 0.25 & 0.19 & $\mathbf{- 0 . 4 5 0 *}$ & $\mathbf{0 . 0 1 4}$ & -0.163 & 0.399 & 0.198 & 0.304 \\
Aug & 0.176 & 0.361 & $\mathbf{- 0 . 4 3 2 *}$ & $\mathbf{0 . 0 1 9}$ & 0.101 & 0.602 & -0.07 & 0.717 \\
Sep & 0.167 & 0.387 & $\mathbf{- 0 . 5 4 2} * *$ & $\mathbf{0 . 0 0 2}$ & 0.191 & 0.322 & -0.096 & 0.621 \\
Oct & 0.266 & 0.164 & $\mathbf{- 0 . 5 2 5 * *}$ & $\mathbf{0 . 0 0 3}$ & 0.036 & 0.851 & -0.116 & 0.547 \\
Nov & -0.021 & 0.916 & -0.305 & 0.108 & 0.029 & 0.881 & 0.118 & 0.541 \\
Dec & -0.137 & 0.479 & -0.183 & 0.341 & -0.174 & 0.366 & 0.019 & 0.921 \\
Annual & $.427^{*}$ & 0.021 & $\mathbf{- 0 . 7 6 1} *$ & $\mathbf{0 . 0 0 0}$ & 0.081 & 0.674 & 0.041 & 0.833 \\
\hline
\end{tabular}


Table 2. The correlation between DS and precipitation of previous year $(N=29)$

\begin{tabular}{|c|c|c|}
\hline & Precipitation & The change rate of precipitation \\
\hline Pearson Correlation & -0.335 & $-0.376^{*}$ \\
Significant (bilateral) & 0.075 & 0.044 \\
\hline
\end{tabular}

\section{Multiple stepwise regression analysis model and reconstruction model}

In view of the correlations between DS and MAT and PCR, multiple stepwise regression analysis was applied. The result reveal that MAT was the only variable entered in the stepwise regression model of DS ( $D S=23.645-0.608 M A T, R^{2}=0.580$, $\left.\bar{R}^{2}=0.564, p=0.000\right)$. So the Tamarix leaf DS values (DSt) can be used as a regression factor to reconstruct $\operatorname{MAT}\left(\hat{T}_{t}\right)$, the MAT reconstruction equation is as follow:

$$
\begin{array}{rcc}
\multicolumn{3}{c}{\hat{T}_{t}=27.668-0.953 * D S_{t}} \\
\text { se } & (2.534) & (0.156) \\
p-\text { value } & {[0.000]} & {[0.000]} \\
R^{2}=0.580, & \bar{R}^{2}=0.564
\end{array}
$$

The curve of reconstructed temperature were shown in Figure 3.
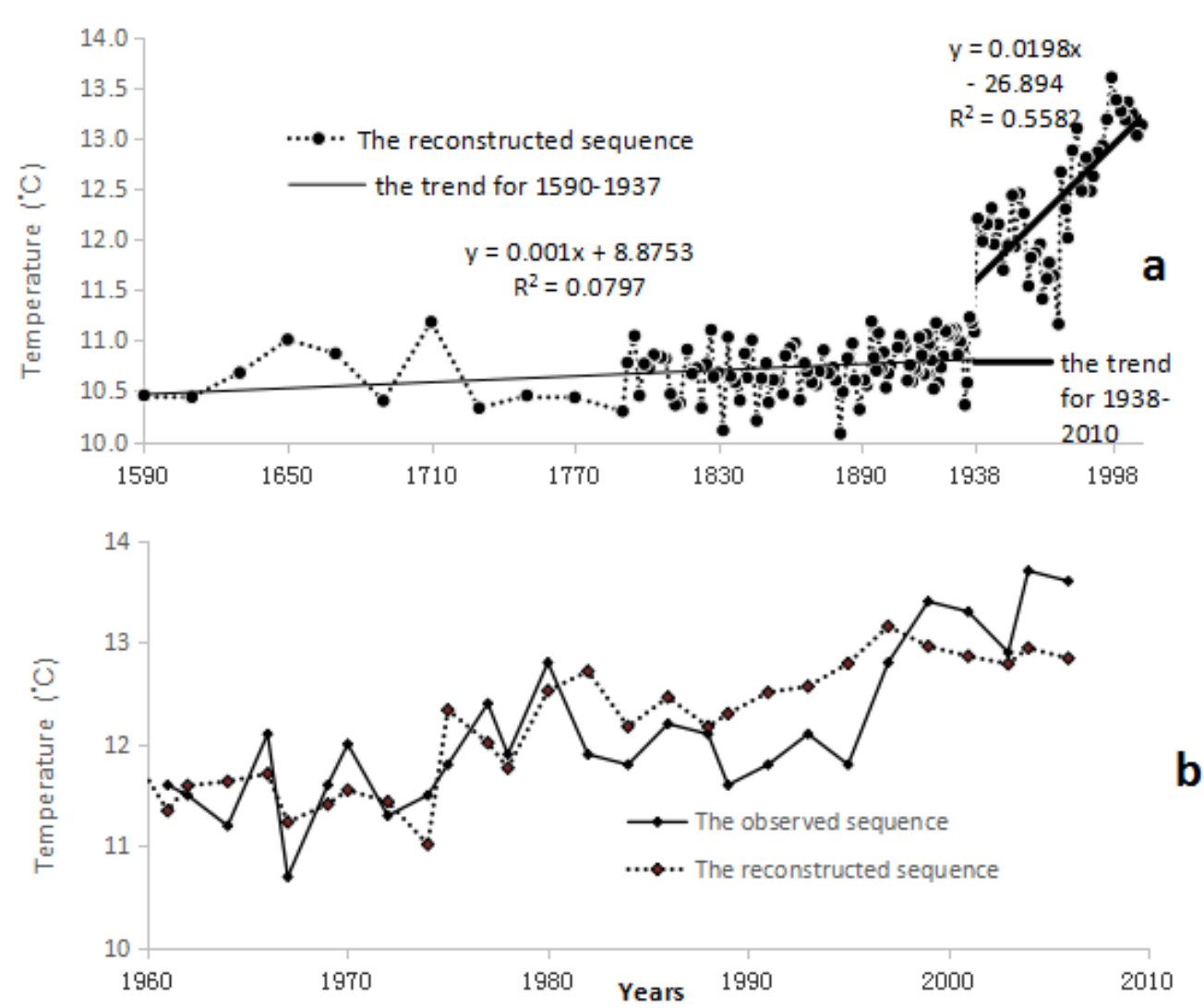

Figure 3. (a)The reconstructed temperature from 1590-2010 and (b)the comparison between the observed and reconstructed temperature from 1960-2010 


\section{Disscussions}

\section{Features of the $\delta 13 C$ values}

The trend of Tamarix leaf $\delta^{13} \mathrm{C}$ values from Cele region in TDSM is characterized by vibration and complexity. The values are very close to those in the Minfeng Andier ancient city and the Andier meadow sampling site (Sun, 2013), consistent with the results of Lop Nur region (Xia et al., 2004; Zhao et al., 2011a). The results are basically in accordance with the $\delta 13 \mathrm{C}$ composition of $\mathrm{C} 3$ plants in arid environments (Ehleringer and Monson, 1993).

This results show that the difference of Tamarix leaf $\delta^{13} \mathrm{C}$ values in different sites of TDSM is tiny. The $\delta 13 \mathrm{C}$ values show small regional differences because the sampling sites are geographically different, which proves that the variation of $\delta^{13} \mathrm{C}$ value of Tamarix leaves in arid regions is stable within species and regions. In addition, compared with the extremely arid Lop Nor region, the hinterland of the desert, the climate of Cele region in TDSM is relatively humid. Therefore, the Tamarix leaf $\delta^{13} \mathrm{C}$ values show a gradual decrease with the improvement of water conditions. This conclusion is similar to that of some conclusions (Liu et al., 1997; Sun et al., 2003; Yun et al., 2010; Zhao, 2012).

\section{Effect of temperature on Tamarix}

The correlation between temperature and DS is more significant than that with $\delta 13 \mathrm{C}$, and the DS sequence is correlated with the temperature in growing season and MAT negatively and significantly (Table 1).Combining the results of stepwise regression, we believe that temperature has exerted the key influence on carbon isotope discrimination of the Tamarix growing in arid area, and the DS decline 0.608 for each degree rise in MAT.

Temperature is one of the most important factors that control plant growth and certain physiological processes related to plant gas exchange activity. A decline temperature usually results in a reduction in enzyme activity and photosynthetic rate (Beerling, 1994), thus leading to decreased $\mathrm{CO}_{2}$ assimilation and a lower growth rate as a consequence. An increase in DS with decreasing temperature is therefore expected and has been observed in most of the studies on the influence of temperature on carbon isotope discrimination (e.g., McCarroll and Loader, 2004; Treydte et al., 2007; Wang et al., 2013).

Our results are consistent with these studies and suggest a decline in DS with increasing temperature. The temperature influences the growth of Tamarix directly, and the higher mean annual temperature of the growing season is more beneficial to Tamarix. That shows an agreement with some researchers (Wang et al., 2003; Liu et al., 2007; Shen and Chen, 2000; Zhao et al., 2011b).

\section{Effect of precipitation on Tamarix}

Numerous studies have reported the influence of water availability on plant carbon isotope discrimination (e.g., Wang et al., 2005, 2008; Diefendorf et al., 2010; Kohn, 2010), and a positive correlation between DS and water availability has been observed on most occasions. The mechanism of water availability on plant carbon isotope discrimination is that the plants would close their stomata to reduce water loss when moisture decreases, resulting in a lower ci/ca ratio and less negative $\delta 13 \mathrm{C}$ values. 
In this study, the $\delta 13 \mathrm{C}$ and DS values are with little dependence on contemporary precipitation but in February $(\mathrm{r}=-0.448, \mathrm{p}=0.007)$ (Table 1). At the same time, correlation analysis (Table 2) is made between DS sequence and the precipitation in the previous year and the precipitation changes rate of previous year (i.e., the natural logarithm of the precipitation in the previous year). The correlation coefficients are 0.335 and $-0.376(\mathrm{p}=0.044)$.

The effect of precipitation on the growth of Tamarix is weaker. Preliminary analysis suggests that in more precipitation year, more snow and ice were deposited on the mountains than normal year, which may result in the larger quantity of underground water availability in growth period of Tamarix in the next year, and consequently promoted the photosynthetic rate and Tamarix growth.

This further proves the "lag effect" of precipitation (Leavitt and Long, 1989) on Tamarix growth. The precipitation is an important factor influencing the growth of Tamarix in arid region, but not directly, and the mechanism is complex.

\section{Analysis of reconstructed temperature in past $400 a$}

The temperature from 1590 to 2010 were reconstructed based on DS (Figure $2 a$ ), could be divided into sub-periods by the year 1937 based on the trend.

The first period (1590 - 1937): It is a 347-year time span. The trend line slanting rate of reconstructed temperature is 0.001 , the temperature were more stable with a slighter fluctuation.

The second phase (1938 - 2010): In the 72 years, the temperature underwent a remarkable increase, the trend line slanting rate is 0.0198 , and its range of oscillation was extended. It can be defined as the modern warm and wet period.

The explained variance of reconstructed mean annual temperature is $56.4 \%$, which is reliable. The results show a tendency toward warming, and the change will be more frequent and more intense, which reflects the characteristics of global climate change.

\section{Conclusion}

The present study conducted an investigation of Tamarix leaf $\delta 13 \mathrm{C}$ in TDSM and analyzed the influence of temperature and precipitation on the variation in DS. Temperature, the key growth-limiting factor for Tamarix, was found a significant influence on DS, but the influence of precipitation was relatively weak. Future study should consider on water availability in relation to Tamarix carbon isotope discrimination. Ecosystems in TDSM are fragile and sensitive to climate change. With the rising temperature, more precipitation will be expected, which may have enormous impacts on productivity and stability of ecosystems in the future.

Acknowledgements. This research was financially supported by the National Natural Science Foundation of China(Grant No. 41071133, 40671188) and the Construction project of key disciplines in Colleges and universities of Hebei Province.

\section{REFERENCES}

[1] Beerling, D. J. (1994): Predicting leaf gas-exchange and C response to the past 30,000 years of global environmental change. - New Phytol 128: 425-433. 
[2] Diefendorf, A. F., Mueller, K. E., Wing, S. L., Koch, P. L., Freeman, K. H. (2010): Global patterns in leaf $13 \mathrm{C}$ discrimination and implications for studies of past and future climate. - Proc. Natl. Acad. Sci. U.S.A. 107: 5738-5743.

[3] Ehleringer, J. R., Monson, R. K. (1993): Evolutionary and ecological aspects of photosynthetic pathway variation. - Annual Review of Ecology \& Systematics 24(1): 411-439.

[4] Farquhar, G. D., Hubick, K. T., Condon, A. G., Richards, R. A. (1989): Carbon isotope fractionation and plant water-use efficiency. - In: Rundel, P. W., Ehleringer, J. R., Nagy, K. A. (eds) Stable Isotopes in Ecological Research. New York, NY: Springer Press, 21 40.

[5] Farquhar, G. D., O'leary, M. H., Berry, J. A. (1982): On the relationship between carbon isotope discrimination and the intercellular carbon dioxide concentration in leaves. Functional Plant Biology 9(2): 121-137.

[6] Friedli, H., Lotscher, H., Oeschger, H., et al. (1986): Ice-core record of the 13C/12C ratio of atmospheric CO2 in the past two centuries. - Nature 324: 237-238.

[7] Kohn, M. J. (2010): Carbon isotope compositions of terrestrial C3 plants asindicators of (paleo) ecology and (paleo) climate. - Proc. Natl. Acad. Sci. U.S.A. 107: 19691-19695.

[8] Körner, C., Farquhar, G. D., and Wong, S. C. (1991): Carbon isotope discriminationby plants follows latitudinal and altitudinal trends. - Oecologia 88: 30-40.

[9] Körner, C., Farquhar, G. D., Roksandic, Z. (1988): A global survey of carbonisotope discrimination in plants from high altitude. - Oecologia 74: 623-632.

[10] Leavitt, S. W., Long, A. (1989): The Atmospheric Delta-C-13 Record as Derived from 56 pinyon Trees at 14 Sites in the Southwest United-States. - Radiocarbon 31(3): 469-474.

[11] Liu, G. S., Qi, C. M., Lin, X. Y., et al. (1997): Reflection of surface runoff variation by tree-ring in its drainage area. - Journal of Changchun University of Earth Sciences 3: 333 336.

[12] Liu, X. H., Shao, X. M., Wang, L. L., et al. (2007): Climatic significance of the stable carbon isotope composition of tree-ring cellulose: Comparison of Chinese hemlock (Tsuga chinensis Pritz) and alpine pine (Pinus densata Mast) in a temperate-moist region of China. - Science in China (D) 7: 1076-1085.

[13] Liu, X. Z., Zhang, Y., Su, Q., et al. (2014): Research progress in responses of modern terrestrial plant carbon isotope composition to climate change. - Advances in Earth Science 12: 1341-1354

[14] McCarroll, D., Loader, N. J. (2004): Stable isotopes in tree rings. - Quaternary Science Reviews 23(7): 771-801.

[15] Morecroft, M. D., Woodward, F. I. (1996): Experiments on the causes of altitudinal differences in leaf nutrient contents, age and 13C of Alchemilla alpine. - New Phytol. 134: 471-479. doi: 10.1111/j.1469-8137.1996.tb04364.x

[16] Seibt, U., Rajabi, A., Griths, H., Berry, J. A. (2008): Carbon isotopes and water use eciency: sense and sensitivity. - Oecologia 155: 441-454.

[17] Shen, J., Chen, Y. F. (2000): The climatic reconstruction from the tree-ring $\delta 13 \mathrm{C}$ values of Cedrus deodara (Roxb.) Loud. during the past 20 years in Nanjing. - Journal of Plant Resources and Environment 3: 34-37.

[18] Sparks, J. P., Ehleringer, J. R. (1997): Leaf carbon isotope discrimination and nitrogen content for riparian trees along elevational transects. - Oecologia 109: 362-367.

[19] Sun, B. N., Dilcher, D. L., Beerling, D. J., et al. (2003): Variation in Ginkgo Biloba L leaf characters across a climatic gradient in China. - PNAS 12: 7141-7146.

[20] Sun, Z. Y. (2013): The climate change revealed by the date-13C values of Tamarix cone sedimentary veins in the south region of Taklimakan Desert. - Shijiazhuang: Hebei Normal University.

[21] Treydte, K., Frank, D., Esper, J., Andreu, L., Bednarz, Z., Berninger, F., et al. (2007): Signal strength and climate calibration of a European tree-ring isotope network. Geophys. Res. Lett. 34: 1-6. 
[22] Wang, G., Feng, X., Han, J., Zhou, L., Tan, W., Su, F. (2008): Paleovegetation reconstruction using $\delta 13 \mathrm{c}$ of soil organic matter. - Biogeosciences 5(2): 1325-1337.

[23] Wang, G., Han, J. M., Liu, D. S. (2003): The carbon isotope composition of C3 herbaceous plants in loess area of northern China. - Science in China (D) 10: 1070-1076.

[24] Wang, G., Han, J., Zhou, L., Xiong, X., and Wu, Z. (2005): Carbon isotope ratios of plants and occurrences of $\mathrm{C} 4$ species under different soil moisture regimes in arid region of Northwest China. Physiol. - Plant 125: 74-81.

[25] Wang, G., Li, J., Liu, X., and Li, X. (2013): Variations in carbon isotope ratios of plants across a temperature gradient along the $400 \mathrm{~mm}$ isoline of mean annual precipitation in north China and their relevance to paleovegetation reconstruction. - Quat. Sci. Rev. 63: 83-90.

[26] Wei, L. L., Zhang, X. Q., Hou, Z. H., Xu, D. Y. (2005): Application of Stable Carbon Isotope Analysis in the Research on Global Climate Change. - World Forestry Research 18(2): 16-19.

[27] Winter, K., Holtum, J. A. M., Edwards, G. E., O'Leary, M. H. (1982): Effect of low relative humidity on (13C value in two $\mathrm{C} 3$ grasses and in Panicum milioides, a C3-C4 intermediate species. - J. Exp. Bot. 33: 88-91.

[28] Xia, X. C., Zhao, Y. J., Wang, F. B., Cao, Q. Y., Mu, G. J., Zhao, J. F. (2004): Stratification features of Tamarix cone and its possible age significance. - Chinese Science Bulletin 49(14): 1539-1540.

[29] Xu, M., Wang, G., Li, X., Cai, X., Li, X., \& Christie, P., et al. (2015): The key factor limiting plant growth in cold and humid alpine areas also plays a dominant role in plant carbon isotope discrimination. - Frontiers in Plant Science 6: e44628.

[30] Yun, H. B. (2010): Research on the seasonal characteristics of $\delta 13 \mathrm{C}, \delta \mathrm{N}$ and nonstructural carbohydrate of main plants in different ecosystems in the inland of QinghaiTibet Plateau. - Xi'an: Northwest Normal University.

[31] Zhao, Y. (2012): Morphological and physiological responses of Populus euphratica leaf to groundwater table variations in the lower reaches of Heihe River. - Lanzhou: Lanzhou University.

[32] Zhao, Y. J., Li, X. F., Xia, X. J., Wang, X. Y. (2011a): C and N contents in organic matter of Tamarix dune sedimentary veins and environmental change in Lop Nur region. Journal of Arid Land Resources and Environment 25(4): 149-154.

[33] Zhao, Y., Wang, X., Xia, X., Li, X. (2011b): The $\delta^{13} \mathrm{C}$ sequence of Tamarix cone sedimentary veins and climate reconstruction during last 160 years in Lop Nur region, Xinjiang, China. - Quaternary Sciences 31: 130-136.

[34] Zhao, Y. J., Liu, H., Che, G. H., Wang, H., Gao, C. J., Xia, X. C. (2015): On age sequence establishment method of Tamarix Cone Sedimentary Veins in desert region. Arid Zone Research 32(4): 810-817. 